lower end of the sternum and the other to the apex he found that when both chest-pieces were in position a double first sound was heard; when, on the other hand, either chestpiece was applied separately the sound was single. He was thus able to establish that of the two parts of the sound the one was originated in connexion with the right ventricle, the other in connexion with the left.

If the hypothesis be correct that the double first sound is due to a lack of coincidence in the moments at which the mitral and tricuspid valves, being thrown into tension, give rise to sound, it is interesting to note that reduplications of the first and of the second sounds fall into line as regards the essential mechanism of their production. In both cases the doubling is attributable to asynchronous valve tension ; there is, however, the difference that the second sound is purely one of valve tension and it is accordingly possible for the aortic and pulmonary elements to be completely separated with the result of perfect reduplication; whereas in the production of the first sound other factors besides valve tension are concerned and the separation of the valvular factor into its two component parts, mitral and tricuspid, does not lead to a complete division or reduplication of the sound. The view of asynchronous valve tension involves no loppothetical dissociation of one ventricle from the other in respect of muscular contraction; it is not inconsistent with a ventricular systole that from beginning to end is concurrent on the two sides. Nor does it imply a want of synchronism between the right and left sets of musculi papillares; by the shortening of these muscles the valve segments are doubtless drawn together, but it remains to be shown that their approximation exactly coincides with the moment at which the valve tension becomes such as to give rise to sound; it would, indeed, seem on a priori grounds that the closure of the valves must be completed as a preliminary to the rapid rise of intra-ventricular pressure which is necessary for the production of sufficient tension to cause a valvular sound. What reduplication really signifies is a lengthening of the period between the closure of the valve and the production of sound on the side of the ventricle which has to meet the greater relative resistance.

It is sometimes assumed that the systole of the relatively burdened ventricle is prolonged, outlasting that of its fellow. This I do not believe to be commonly the case. If it were so the closure of the semilunar valves on the affected side would be delayed and the double first sound would be followed by a double second sound. As a matter of fact, combined reduplication of both sounds is uncommon; with reduplicated first sound the second sound is usually accentuated but not doubled, the accent falling on the pulmonary or aortic sound according to the associated conditions in regard to pulnonary and aortic tension. The increased resistance is probably overcome by an increased vigour of contraction on the part of the ventricle concerned sufficient to compensate for the initial delay and to bring the systole to a close at the same moment on the two sides. It is sometimes stated that as regards prognosis a double first sound is an indication of undue stress and of impending cardiac failure. The statement is not borne out by my experience in the above series of cases. The greater number of the patients were occupied with their usual work and only attended hospital as out-patients. Patients have been under my observation for more than a year in whom the abnormal sound has persisted without change in its character and without any sign of cardiac failure.

Weymouth-street, $\mathrm{W}$.

\section{A NEW DEPARTURE IN THE TREATMENT OF HYPOPYON KERATO-IRITIS. ${ }^{1}$}

\section{By G. HERBERT BURNHAM, M.D. TORONTO,} F.R.C.S. EDIN.

ASSOCYATE PROFESSOR OF OPHTHALMOLOGY AND OTOLOGY AT THE UNIVERSTYY OF TORONTO, ETC.

MY remarks will solely deal with the most severe type of the disease-in other words, with that form which tests the relative ralue of diverse treatments. I have, I may say, vividly before my mind three cases of the disease, in

1 A note read at the annual meeting of the Canadian Medical A note read at the annual meeting of the Canadia
Association held at Mont real, Canada, in September, 1902. each of which the duration of time since the onset of the disorder had varied from three to eight weeks, so that the affection had become thoroughly seated and in cluded a severe cyclitis as well. The infiltration in each case occupied the centre of the cornea to an extent larger than the area of the pupil, and the pus in the anterior chamber was on a level with the lower margin of the pupil. The pupil was also bound down and dilated but little, if at all, under the use of atropine. The eyeball was deeply injected and the pain was severe and long-continued. The treatrnent always advocated and relied upon is the local, and internal-i.e., constitutional-remedies occupy a decidedly secondary place. I shall not rehearse the list of local remedies, which is long and in many ways of great merit. However, in the type I am speaking of, where the corneal tissue is so extensively diseased, their use often fails to check the downward progress or, if it does, so tardily that great damage is the outcome. My treatment is purely constitutional, save the dropping into the eye of a four-grain solution of atropine once every day or second day, and the casual bathing of the eye with hot water or a little boric acid. It consists in the use of my combined treatment-viz., mercury and iodide of potassium taken internally and pilocarpine given hypodermically. For guidance as to the administration of this treatment I beg to refer to my papers in the Archives of Ophthalmology, the Ophthalmic Review, and THE LANCET." The results have been truly satisfactory. The apward trend of the disease has soon showed itself in the pain being quickly relieved, in the infiltration having a sharper margin, in the pus in the anterior chamber lessening, and in the surrounding healthy cornea becoming brighter and clearer. And, moreover, the improvement once established ever remains-i.e., no relapse takes place. In one case that came very late under my care and looked truly desperate before the disease could be checked a leakage began to take place through the ulcer so that the iris lay against the cornea. Even here the result turned out well and the adherent tissue has gradually given away, so that now there is a very fair anterior chamber.

In this treatment, moreover, the opacity left keeps ever growing less in size and denseness, so that finally it will disappear or only a non-disfiguring opacity be left. This treatment has several excellent features - the rapid relief of pain, the cure of the diseased condition with at least as great certainty as by the other methods and, I am fully persuaded, with greater, the gradual and uniform removal of the corneal opacity, and the absence of any pain immediately aşsociated with the form of treatment used.

Thus, again, the eye allows to be demonstrated the great effect that a group of remedies given as mine are can, and do, exert upon a very severe type of an acute disease with marked degenerative changes.

And again let me say, as I am ever doing, if the eye thus responds to this treatment, may not other organs and parts of the body be rightly deemed just as susceptible to its influence?

Toronto.

\section{A CASE OF CONCEALED ACCIDENTAL HAMORRHAGE.}

By J. W. INGLES, M.B., Ch.B. EdiN.,

Latie MEDICAL OFFICER, DUNDEE PaROCHIAT, HOSPITaL.

ToE patient was a full-time, healthy multipara, aged 40 years. I was called to attend in her confinement about $10 \mathrm{~A} . \mathrm{M}$. I went immediately and was told by a midwife who was in attendance and who had been so for the greater part of the previous night that the patient was all right and was making satisfactory progress, and that the "colours had broken," but that she did not think the child would be born for some time. She had sent for me before I went my usual " rounds."

I examined the patient and found her pulse to be beating 112 per minute and soft. She was having strong pains regularly, which were to all appearances normal, but the patient said that she did not think that they were real labour pains. Her general appearance seemed normal. I then 
examined the abdomen which was globular. I could not make out the foetus, but what aroused my suspicions was the fact that immediately $I$ put my hand on the patient's abdomen there was an obscure feeling of crepitus of a similar character to that which is felt in a severe bruise with extravasated blood but by no means distinct. I concluded that the uterus might contain blood and found on inquiry that tre patient was, as a rule, "full. blooded"; also that she had been stretching herself while papering a room on the previous day and had not felt well since I asked to see all the cluthes and cloths she had used and all th- blood she had lost, if any. I was shown about 40 drops on a clean linen cloth which she had used : there was no blood serum or mucus. This was what the attendant had in her mind when she told me that the "colours had broken." The blood drops were perfectly clear and fresh.

Un examination per vaginam the passages were found to be normal ; the os was normal and dilated to admit two fingers while nothing unusual was to be felt in the vicinity. The presentation was normal and the membranes were intact but my fingers after the examination had on them a little fresh blood. There was no hæmorrhage taking place externally. Taking into consideration the patient's previous day's work, her pulse, her pallor (which was not abnormal but for the fact that the woman in health was "full-blooded"), the fact that her pains were not in character what they ought to be according to the patient's statement, the freshness of the few drops of blood which were external, and more especially the slight obscure crepitus on palpation and the globular appearance of the abdomen, I concluded that this was a case not often met with by the general practitioner-namely, a case of concealed accidental hæmorrhage.

I decided that immediate delivery was the best course to adopt, so I sent for assistance and proceeded to dilate the os with my fingers ; during this time no blood escaped externally. By the time assistance had arrived the os was well dilated. We ruptured the membranes and liquor amnii escaped mixed with blood. By this time the pulse was occasionally imperceptible, so we put on forceps and when the first blade passed the head blood poured out ; the child was immediately delivered and along with it the cord, membrane: and placenta came away all in one. The child was dead and the placenta looked as if it had been separated for some time. Following this the uterus, which was full of large clot;, was emptied of blood and well contracted by manipulation and ergot. No blood was lost after this and contraction was obtained immediately the uterus was emptied. The patient had the same appearance and her mind remained very clear. Her pulse varied, being sometimes perceptible and sometimes imperceptible. I gave her stimulants constantly. Saline rectal injections were given but the poor woman gradnally became pulseless and collapsed. Crieff, N.B.

\section{EOSINOPHILIA ASSOCLATED WITH BILHARZIA DISEASE.}

BY A. E. RUSSELL, M.D., M.R.C.P. LoND., M.R.C.S. ENG., ASSISTANT PHYSICIAN, WEST LONDON HOSPITAL; DEMONSTRATOR OF PHYSIOLOG $X$, S'I. THOMAS'S HOSPITAL.

THE occurrence of a well-marked eosinophilia in many of the diseases of man caused by parasites such as trichina spiralis, ankylostoma duodenale, \&c., is now becoming well recognised. Dr. C. G. Seligmann and Mr, L S. Dudgeon ${ }^{1}$ in a case of hydatid disease found on one estimation that the eosinophiles were present in the blood in the enormous proportion of 57 per cent. of all the leucocytes, confirming Neusser's observation on the increase of the eosinophile cells in hydatid disease. Dr. A. C. Coles has published a case of bilharzia disease ${ }^{2}$ in which he found that 20 per cent, of the leucocytes were eosinophiles. This I believe to be the only case so far recorded. The rarity of the disease in the general hospitals prevents any examination of a series of cases and must be my excuse for publishing an isolated case after attention has already been drawn to the occurrence of eosinophilia in it.

1 Eosinophilia associated with Hrdatid Disease, The LancrT, June 21st, 1912 , p. 1764

2 The Bloud in Cases affected with Filariasis and Bilharzia Hæmatobia, Brit. Med. Jour., May 10th, 1902.
The patient was a young man, aged 25 years, who served in the South African campaign from December, 1899, to May, 1901. He took part in Lord Roberts's march across the Free State and was present at Paardeberg, where he drank freely of the polluted river water. He developed a cough and had slight hæmoptysis for which $h \rightarrow$ was invalided out of the service. His journey throutgh Natal to the coast took nine days, mainly spent in the train. While on board ship on the way home he had attacks of pain in the loins but no urinary trouble. He reached home on May 23rd, 1901, and four weeks later he noticed for the first time that his urine wa; blood-stained at the end of micturition. The patient was positive that up to this time his urine had been perfectly normal. This passage of blood with the urine had persisted ever since. He was admitted into the West London Hospital under the care of Dr. Seymour Taylor on May 24th, 1902, and was discharged on June 14th. He was in fair condition, though somewhat anæmic in appearance. The urine varied as regards the amount of blood it contained but the quantity was usually small ; blood clots were frequently present. The typical bilhaxzia ova were always to be found in large numbers as well as bladder epithelium. Small patches of bladder epithelium and clot containing numbers of ova were common. Red blood corpuscles were always present. A blood count showed 10,000 leucocytes and $4,770.000$ red cells per cubic millimetre and 60 per cent. of hæmoglobin. He still complained of occasional pains in the loins and stated that when the pain was more severe he had noticed that his urine contained more blood. His stools were examined but no blood was ever seen. He had, however, passed blood with his stools before admission to hospital, but as he had suffered from an attack of dysentery while in Bloemfontein in April, 1900, this might well have been due to that. He was readmitted on August 27th in precisely the same condition and his blood was examined on ihree occasions more fully. For two of the estimations I am indebted to Mr. L. S. Dudgeon. On the first occasion the blood was taken just before the patient's dinner (on Sept. 1st), on the second four hours after dinner (on Sept. 6 th), and on the third one and a half hours after breakfast (on Sept. 30th). The results were as follows :-

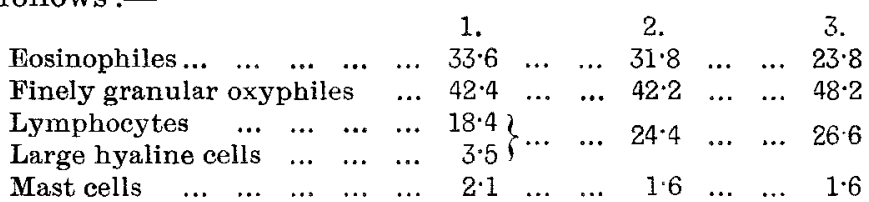

On the third occasion the leucocytes numbered 7500 per cubic millimetre and the red cells 5,037,000. The hæmoglobin percentage by Oliver's hamoglobinumeter was 100 . It is interesting to note that the firt sign of bæmaturia occurred one month after landing in England-i.e., about seven weeks after leaving South Africa. As usual, nothing: can be inferred as to the mode of infection; he had drunk polluted river water but had only bathed three times.

St. Thomas's Hospital.

\section{A a ditrrot}

\section{HOSPITAL PRACTICE,}

\section{BRITISH AND FOREIGN.}

Nulla autem est alia pro certo noscendi via, nisi quamplurimas et morborum et dissectionum historias, tum aliorum tum propria collectas habere, et inter se comparare.-MorgagNI De Sed. et Caus. Morb., lib. iv., Procemium.

\section{WEST LONDON HOSPITAL.}

TWO CASES OF CESOPHAGEAL OBSTRUCTION BY COINS.

(Under the care of Mr. H. W. BAYLY and

Dr. J. LEWES TIMMTNS.)

Corss are very frequently swallowed, especially by children, and in most cases they pass with little trouble through the whole alimentary canal. Occasionally, however, they lodge in the cesophagus, and the three most common situations at which they are arrested are at the commencement of the csophagus. opposite the bifurcation. 